\title{
Mediating the Effect of Gratitude in the Relationship between Forgiveness and Life Satisfaction among University Students
}

\author{
Ahu Arıcıoğlu ${ }^{1}$ \\ ${ }^{1}$ Department of Counseling and Guidance, Faculty of Education, Pamukkale University, Denizli, Turkey \\ Correspondence: Ahu Arıcıoğlu, Department of Counseling and Guidance, Faculty of Education, Pamukkale \\ University, Denizli, Turkey
}

Received: March 28, 2016

Accepted: April 15, 2016

Online Published: April 19, 2016

doi:10.5430/ijhe.v5n2p275

URL: http://dx.doi.org/10.5430/ijhe.v5n2p275

\begin{abstract}
The purpose of this study was to examine the mediating effect of gratitude in the relationship between forgiveness and life satisfaction. A convenience sample of 396 (234 (59\%) females, 162 (41\%) males) university students was recruited from a University in Denizli, Turkey. The participants' ages ranged between 18 and 27 years, with an average of 20.90 years $(\mathrm{SD}=1.60)$. Of the participants, $101(26 \%)$ were freshman, $81(21 \%)$ were sophomores, 114 (29\%) were juniors, and 100 (25\%) were seniors. The Gratitude Questionnaire, Heartland Forgiveness Scale and Satisfaction with Life Scale were used for the data collection. Results showed that gratitude partially mediated the relationship between forgiveness and life satisfaction. The results, limitations and implications of the study were discussed.
\end{abstract}

Keywords Forgiveness, Gratitude, Life satisfaction, University Students

\section{Introduction}

Traditional age university students face numerous challenges through their college years. They have to deal with normative developmental tasks while at the same time struggling with separation from family and adapting to a new environment. On the other hand, they are faced with greater academic challenges than ever before. In other words, the young persons need to establish new relationships, explore and refine various aspects of their identities, cope with academic demands and influences of their peers and the popular culture. The fact that the educational system in Turkey is geared toward the university entrance exams and thus the students often begin a tedious preparation process for these exams at elementary school years appears to interfere with the students' developmental needs. Therefore, they often enter universities without having the chance to sufficiently deal with the tasks of previous developmental stages (Ceyhan, 2011). This might pose additional challenges to the university students in Turkey.

As Sanford $(1962,1966)$ insistently noted that in order for the contemporary university to foster optimum developmental growth and learning there must be a reasonable balance between the support and the challenges the students encounter through their college experience. A great deal of such support is provided by student personnel services which do not yet operate at a professional level in Turkish universities. In other words, individuals working at different student affairs offices do not only lack specialized training but also their services are not devised in accordance with an existing body of research. Likewise, of central importance to the student services are counseling and other mental health services which also seldom exist on Turkish university campuses. In addition to the vital need for establishing mental health and other student services at Turkish universities, there is also crucial need for an accumulated body of research to guide these services. Therefore, this study attempts to contribute to basic research efforts that will guide the student services in Turkey. There is an urgent need for exploring protective and risk factors associated with university students' adaptation and development. Thus, the purpose of this study was to explore the mediating effect of gratitude in the relationship between forgiveness and life satisfaction among the university students.

\subsection{Forgiveness}

There are various definitions of forgiveness: According to Enright (1996), "forgiveness is a willingness to abandon one's right to resentment, negative judgment, and indifferent behavior toward one who unjustly injured us, while fostering the undeserved qualities of compassion, generosity, and even love toward him or her" (p.113). 
"Forgiveness occurs in response to an interpersonal violation and involves mending emotional wounds, restoring trust, and repairing the relationship bond" (Makinen \& Johnson 2006, p. 1056).

Forgiveness involves cognitive (Flanigan, 1992), affective (Malcolm and Greenberg 2000), behavioral (Gordon et al. 2000), motivational (McCullough et al. 1997), decisional (DiBlasio, 1998), and interpersonal (e.g., Baumeister et al. 1998) dimensions. Researchers do not agree about which dimensions are the most important" (Worthington \& Scherer 2004). Worthington (2003) offers two types of forgiveness: decisional forgiveness and emotional forgiveness. The former one refers to behavioral intentions. For example, the person may decide to forgive just to rid him or herself of the burden but may still feel sad, angry, anxious and be ruminating over the idea of retaliation. In this case, the victim has made a decision to forgive and yet his or her negative feelings toward the perpetrator still continue. On the other hand, decisional forgiveness may facilitate emotional forgiveness as well. Emotional forgiveness, on the other hand, is closely related to motivation. When a person emotionally forgives her or him, she or he no longer holds negative emotions for the perpetrator (Worthington \& Scherer, 2004).

Sometimes forgiveness involves one's re-evaluation of the meaning of the situation at hand and thus operates as a coping strategy. In other cases when it is used as a tool in solving interpersonal issues, it functions as a problem-focused coping strategy. On the other hand, forgiveness is often seen as an affective coping mechanism (Worthington \& Scherer, 2004) and is closely associated with mental health, physical well-being and positive affect (Berry \& Worthington 2001). Some researchers insistently emphasize forgiveness process in terms of coping (Pargament \& Rye, 1998; Strelan \& Covic, 2006; Worthington \& Scherer, 2004). For instance, Strelan and Wojtsiak (2009) found that individuals use similar coping strategies for both general stressors and interpersonal hurt. Hence, forgiveness appears to function as a coping mechanism which involves re-evaluation of the given situation and helps the forgiving personregulate his or her affect and thus eliminates negative feelings. Studies also show that forgiveness has a variety of positive functions including mental strengthening well-being, psychical health, buffering against the interpersonal stressors and allowing compromising and reconciliation (Finkel et al. 2002; Worthington 2005).

Some authors define forgiveness as a process through which one's feelings, thoughts and behaviors gradually shift from negative to positive ones. Studies on forgiveness consistently find links between forgiveness and mental (McCullough \& Witvliet, 2002) as well as physical health (Lawler-Row, Hyatt Edwards, Wuensch \& Karremans, 2011). Likewise, other researchers have found negative relationships between forgiveness and depression (Brown, 2003) and between forgiveness and the need for belonging (Lawler-Row, Hyatt Edwards, Wuensch \& Karremans, 2011). Some authors also report that individuals with low self-esteem are less likely to forgive (Eaton et al. 2007). In sum, forgiveness is positively correlated with mental and physical health and with one's level of life satisfaction (Worthington, Berry \& Parrott, 2001; Thompson et al. 2005).

\subsection{Life Satisfaction}

Subjective well-being includes three basic dimensions: (1) individual's cognitive evaluation of her satisfaction of private and public aspects of her life, (2) the presence of positive affect, and (3) the absence of negative affect. (Diener, 2000). Life satisfaction is often used as synonymously with the concept of happiness in the field of positive psychology refers to the cognitive aspect of subjective well-being. According to Diener (2000), subjective well-being has an emotional dimension comprising of negative and positive feelings and a cognitive dimension as life satisfaction, which refers to one's cognitive evaluations and judgements about his or her life (Diener \& Suh, 1997). Thus one's life satisfaction has to have a congruence between where the person is and where he or she wishes to have been. If the two are closer to one another, one's perceived level of life satisfaction would be expected to be higher (Diener, Oishi \& Lucas, 2003). A great deal of researches shows that presence of positive emotions and a lack of negative ones is closely associated with life satisfaction. (i.e., Levinsohn et al., 1991). Studies have documented that while variables such as gender, race, income has no or little impact on life satisfaction, those such as personal dispositions, close relationships and culture have been found predictive of life satisfaction (i.e., Myers \& Diener, 1995). Likewise, the studies show significant positive relationships between gratitude and life satisfaction (Emmons \& McCullough, 2003; McCullough, Emmons \& Tsang, 2002).

\subsection{Gratitude}

Gratitude is one of the protective aspects of personality that has gained a research attention in recent years. In general, gratitude is conceptualized as both a disposition and a state or emotion. As a disposition, gratitude is viewed as an enduring characteristic of thankfulness that is sustained across situations and over time (McCullough, Emmons \& Tsang, 2002; cited in Chan, 2013). Accordingly, grateful individuals would be more likely experienced and express thankfulness in responding to benefits or gifts from others. As a state, the occurrence of gratitude is typically 
associated with the perception of receiving an undeserved personal benefit due to the good intentions of another person (Emmons \& McCullough, 2003; cited in Chan, 2013). Although gratitude has been viewed as an emotion, personality trait, moral value or a coping mechanism, in recent years a stronger emphasis has been placed on the affective dimension of the concept and its conceptualization as a personality disposition (Yüksel \& Oğuz Duran, 2012).

Gratitude is viewed as both a normal and a normative aspect of personality and social life (McCullough, Kilpatrick, Emmons \& Larson, 2001). It is described as the positive emotion one feels when another person has willingly given, or intends to give, something needed or valued (McCullough, Kilpatrick et al., 2001; McCullough \& Tsang, 2004). "Fostering gratitude appears to provide a wide range of benefits across multiple domains, including domains of mental health, physical health, and social well-being" (Lambert, Fincham, Graham \& Beach, 2009). Grateful feelings strengthen social relationships and help people cope with stressful situations (Lyubomirsky, Sheldon \& Schkade, 2005). Thus, the research on gratitude may provide new insight into the interplay of interpersonal relationships and well-being.

Grateful thinking fosters the savoring of positive life experiences and situations, so that individuals can extract the maximum possible satisfaction and enjoyment from their circumstances (Sheldon \& Lyubomirsky, 2006). "Gratitude and forgiveness are conceptually connected as pro-social, empathy-based character strengths and are associated with psychological and physical health" (Breen, Kashdan, Lenser \& Fincham, 2010, p. 932). The Studies show that both gratitude (McCullough et al., 2002) and forgiveness (Wade, Bailey \& Shafer, 2005) can be improved with psychological interventions and that they both positively contribute to one's well-being.

Gratitude has prosocial nature; therefore, positively related to forgiveness (McCullough et al., 2002). Previous studies have demonstrated that gratitude and forgiveness are connected to well-being, positive affect, and life satisfaction (Worthington et al., 2001; McCullough et al., 2002; McCullough \& Hoyt, 2002; McCullough, Tsang \& Emmons, 2004; Toussaint \& Friedman, 2009). Forgiveness and gratitude are defined as relational virtues because they govern the process of strengthening and repairing relationships (Dwiwardani et al, 2014) and both are associated with life satisfaction (McCullough et al., 2002 ; McCullough \& Hoyt, 2002; McCullough, Tsang \& Emmons, 2004).

The main purpose of this study was to examine whether gratitude might play a mediating role between forgiveness and life satisfaction. It is aimed at contributing to the literature on forgiveness, gratitude and life satisfaction and to guide researchers and practitioners in intervention program development with Turkish university students.

\section{Method}

\subsection{Participants and Procedure}

A convenience sample was used in this study. Sample of the study consists of voluntary students from various departments in the Faculty of Education. Three hundred ninety-six (234 ${ }_{(59 \%)}$ females, $162_{(41 \%)}$ males) university students were recruited from a University in Denizli, Turkey. Denizli is located in the Southwest of Turkey, and it has a population about one million persons. The participants' ages ranged between 18 and 27, with an average of 20.90 years $(\mathrm{SD}=1.60)$. Of the participants, $101_{(26 \%)}$ were freshman, $81_{(21 \%)}$ were sophomores, $114_{(29 \%)}$ were juniors, and $100_{(25 \%)}$ were seniors. the participants completed the measures during their regular class meetings. the participants could answer the questionnaires at their own pace and typically took about $15 \mathrm{~min}$ to complete all sections.

\subsection{Measures}

\subsubsection{Forgiveness}

Forgiveness was measured with the Heartland Forgiveness Scale (HFS) by Thomson, Snyder, and Hoofman (2005). The scale has 18 items (e.g., Although I feel bad at first when I mess up, over time I can give myself some slack) with a 7-point Likert scale (1= Almost always false of me, $5=$ Almost always true of me). The scale consists of three subscales; forgiveness of self, forgiveness of others, and forgiveness of situations. Also, the scale provides a total forgiveness score. The Turkish version of Heartland Forgiveness Scale was adopted by Bugay, Demir, and Delevi (2012). The Turkish version has been confirmed of HFS structure $\left(\chi^{2} / \mathrm{df}=2.65\right.$; GFI $=.96$, CFI $=.97$, RMSEA $=.04$, and SRMR $=.03$ ) and demonstrated to have good internal reliability (ranged from $\alpha=.71$ to $\alpha=.82$ ). In the current study, the Cronbach alpha coefficient for this scale's dimensions were $0.75,0.77$, and 0.76 , respectively.

\subsubsection{Gratitude}

Gratitude was measured with the Gratitude Questionnaire (GQ) by McCullough, Emmons and Tsang (2002). The original version of the scale has six items (e.g., I have so much in life to be thankful for) with a 7-pointLikert scale (1 
$=$ strongly disagree, $7=$ strongly agree). Adaptation of the Turkish version of Gratitude Questionnaire was done by Yüksel and Oguz-Duran (2012). Turkish version has been confirmed of GQ structure with five items $\left(\chi^{2}=76.5 \mathrm{df}\right.$ $=5 ; \mathrm{GFI}=.97, \mathrm{CFI}=.94, \mathrm{AGFI}=.90$, and SRMR $=.04)$ and demonstrated to have good internal reliability $(\alpha=.77)$. In the current study, the Cronbach alpha coefficient for this scale was 0.80 .

\subsubsection{Life Satisfaction}

Life satisfaction was measured with the Satisfaction with Life Scale (SwLS) by Diener, Emmons, Larsen, and Griffin (1985). The scale consists of five items (e.g., In most ways my life is close to my ideal) with a 7-point Likert scale $(1=$ strongly disagree, $7=$ strongly agree). Adaptation of the Turkish version of Satisfaction with Life Scale was done by Durak, Senol-Durak and Gencoz (2010). The Turkish version has been confirmed of SwLS structure with five items $\left(x^{2} / \mathrm{df}=2.06, \mathrm{IFI}=.99, \mathrm{TLI}=.98, \mathrm{CFI}=.99, \mathrm{SRMR}=.020\right.$, and RMSEA $\left.=.043\right)$ and demonstrated to have good internal reliability $(\alpha=.81)$. In the current study, the Cronbach alpha coefficient for this scale was 0.82 .

\subsection{Data Analysis}

Descriptive statistics and correlation analyses were conducted using IBM SPSS Statistics version 20. In order to analyze the mediation effect, a two-step procedure of structural equation modeling (SEM) recommended by Anderson and Gerbing (1988) via AMOS was used. First step, confirmatory factor analysis was used to examine the relationships between the latent constructs and the indicator variables in a measurement model. Second step, a structural equation model was developed to investigate direct and indirect effects. The goodness-of-fit of the model evaluated by the Standardized Root-Mean-Square Residual (SRMR), Root Mean Square Error of Approximation (RMSEA), Comparative Fit Index (CFI), Goodness-of Fit Index (GFI), and Chi-square $\left(x^{2}\right)$.

\section{Results}

\subsection{Descriptive Statistics and Correlations among the Study Variables}

Correlations among forgiveness, gratitude, and life satisfaction are presented in Table 1. Forgiveness was significantly and positively correlated with gratitude $\left(r=.44, \mathrm{CI}_{95}=.36, .52\right)$ and life satisfaction $(r=.39$, $\left.\mathrm{CI}_{95 \%}=.30, .47\right)$. In addition, gratitude was significantly and positively correlated with life satisfaction $(r=.41$, $\left.\mathrm{CI}_{95 \%}=.32, .49\right)$. It can be seen that all variables were normally distributed; skewness $=-.55$ to .41 , kurtosis $=-.25$ to .05 .

Table 1. Correlations and descriptive statistics of the study variables

\begin{tabular}{llllllll}
\hline Variable & 1 & 2 & 3 & Mean & SD & Skewness & Kurtosis \\
\hline 1. Forgiveness & - & & & 83.82 & 12.71 & .42 & .05 \\
2. Gratitude & $.44^{* *}$ & - & & 25.00 & 5.49 & -.55 & .16 \\
3. Life satisfaction & $.39^{* *}$ & $.41^{* *}$ & - & 21.52 & 5.98 & -.41 & -.25 \\
\hline
\end{tabular}

${ }^{* * *} p<.01$

\subsection{Measurement Model}

Prior to examining mediational model, a series of confirmatory factor analyses (CFAs) was used to assess the properties of the life satisfaction, gratitude, and forgiveness. CFA of life satisfaction including five items demonstrated to fit the data well. Also, CFA of the gratitude including five items revealed to fit the data well. Second order CFA of forgiveness with sub-scales demonstrated a satisfactory fit to the data. Furthermore, the measurement model included three latent factors (life satisfaction, gratitude, and forgiveness) and 13 observed variables were tested through a measurement model and the test of the measurement model came into being a satisfactory fit to the data. All results of the CFAs are illustrated in Table 2.

Table 2. Measurement models of study variable

\begin{tabular}{llllll}
\hline Model & $\chi^{2} / d f$ & CFI & GFI & SRMR & RMSEA \\
\hline CFA of life satisfaction & 3.75 & .98 & .98 & .029 & .073 \\
CFA of gratitude & 5.61 & .96 & .97 & .043 & .079 \\
CFA of forgiveness & 2.86 & .90 & .91 & .60 & .069 \\
Through a measurement model & 2.54 & .94 & .94 & .047 & .063 \\
\hline
\end{tabular}




\subsection{Structural Model}

The baseline model, Model 1, is a fully mediation model that includes the paths from forgiveness to gratitude, gratitude to life satisfaction. In Model 2, a partially mediation model that adding the direct path from forgiveness to life satisfaction. The results demonstrated that Model 1 fits the data well. Also, Model 2 was a good fit to the data. The Model 1 with Model 2 were compared via Chi-squared differences test. The significant Chi-square differences between the two models, $\Delta \chi^{2}(1, \mathrm{~N}=396)=19.28, p<.01$, therefore Model 2 was selected for parsimony. That is, gratitude partially mediated the effect on forgiveness on life satisfaction. Model's fit indices were presented in Table 3. Figure 1 showed the path coefficients of the selected final partially model.

Table 3. Measurement models of study variable

\begin{tabular}{llllllll}
\hline & $\chi^{2}$ & $d f$ & $\Delta \chi^{2}$ & CFI & GFI & SRMR & RMSEA \\
\hline Model 1 - fully mediated model & 177.08 & 63 & - & .93 & .93 & .062 & .068 \\
Model 2 - partially mediated model & 157.80 & 62 & $19.28^{*}$ & .94 & .94 & .047 & .063 \\
\hline
\end{tabular}

Note. ${ }^{*} p<.01$

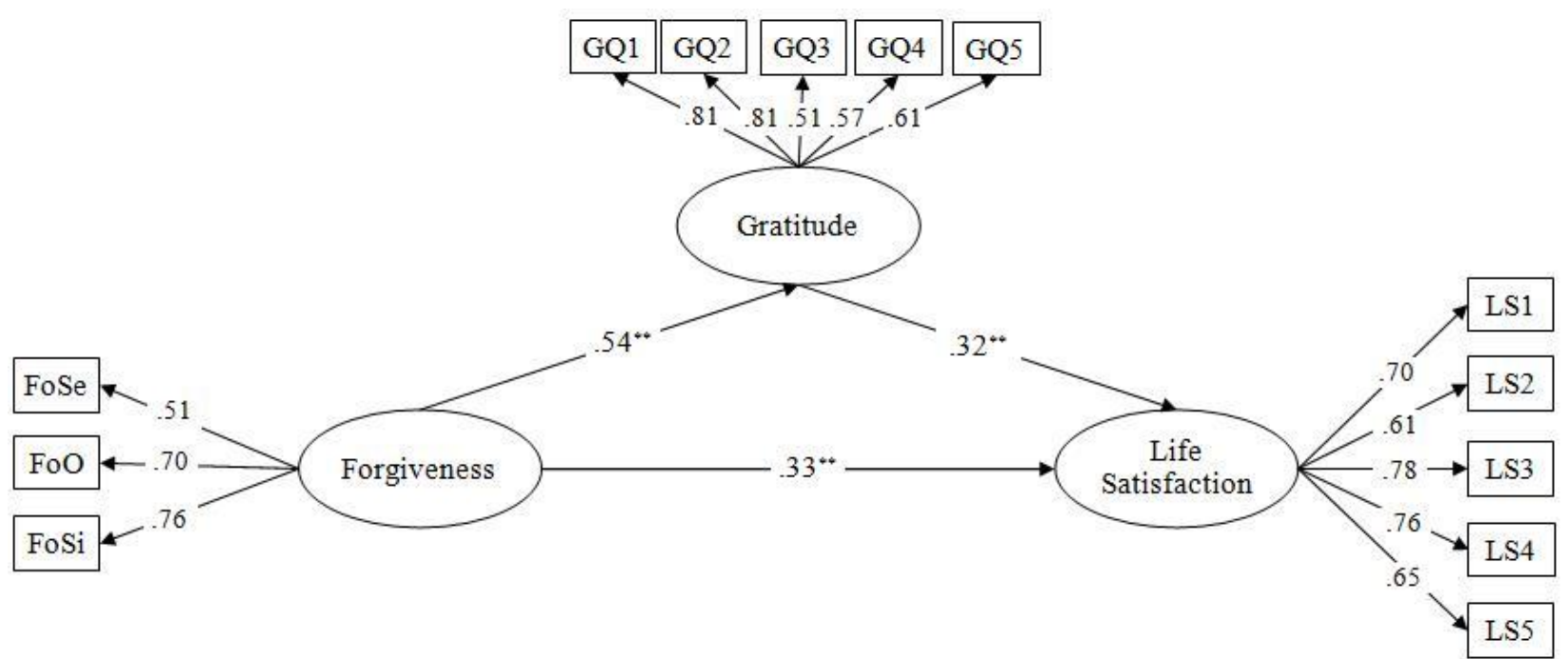

Figure 1. Standardized parameter estimates for the partially mediated structural model. Note: $\mathrm{N}=396 ; * * \mathrm{p}<.01$; FoSe Forgiveness of self; FoO Forgiveness of others; FoSi Forgiveness of situations; GQ item of the Gratitude Questionnaire; LS item of the Satisfaction with Life Scale

\section{Discussion}

The purpose of this study was to examine the mediating role of gratitude in the relationship between forgiveness and life satisfaction. Results showed that the relationship between forgiveness and life satisfaction was partially mediated by gratitude. In other words, the effect of forgiveness on Turkish students' levels of life satisfaction was partially mediated by gratitude. Previous studies with Turkish students have also reported positive correlations between forgiveness and gratitude (Satıc1, Uysal \& Akın, 2014), between forgiveness and life satisfaction (Worthington, Berry \& Parrott, 2001; Thompson et al., 2005), and between gratitude and increased life satisfaction (Emmons \& McCullough, 2003; McCullough, Emmons, \& Tsang, 2002).

This study's result is important for several reasons. The study suggests the importance of gratitude among positive relational characteristics. Gratitude seems to be the variable most significantly predictive of life satisfaction (Paterson et al., 2007). Although no questions regarding participants' beliefs were included in the surveys, one could assume that the great majority of the students were Muslims. Like other major faiths in the world, Islam also regards forgiveness as an important virtue. Thus, similar results might be found in other cultures and religions in which forgiveness is esteemed. 


\subsection{Limitations and Further Research}

When it is considered that a convenience sample of a University students participated in this study, it poses limitations to the generalizability of the results. Therefore, there is need for studies with diverse populations and various age and cultural groups of Turkey. Likewise, work on forgiveness, gratitude and life satisfaction can lead to richer results if longitudinal models are used.

Given the results of this study, the university students will benefit from professional student personnel services including the counseling services. Furthermore, existing curricula can be enriched with a variety of personal growth, related elective courses can foster protective factors among the university students. There have been studies involving the development of intervention programs on forgiveness and their effects of a variety of personal variables (Al-Mabuk, Enright \& Cardis, 1995). Working with Turkish university students, Bugay and Demir (2012) developed a-group intervention program based on Enright's (1996) Forgiveness Process Model and found the program to be effective in fostering forgiving others and general forgiveness. Çardak (2012) also developed a Forgiveness Based Psychoeducational Program and found it significant in enhancing forgiveness in participants. More comprehensive intervention programs involving enhancement of gratitude and forgiveness can incorporate various other indicators of wellbeing to foster university student mental health. Further works with involving intervention programs with Turkish university students are needed.

\section{References}

Al-Mabuk, R. H., Enright, R. D. \& Cardis, P. A. (1995). Forgiveness education with parentally love-deprived late adolescents. Journal of Moral Education, 24, 427-444. http://dx.doi.org/10.1080/0305724950240405

Anderson, J. C. \& Gerbing, D. W. (1988). Structural equation modeling in practice: A review and recommended two-step approach. Psychological Bulletin, 103(3), 423-441. http://dx.doi.org/10.1037/0033-2909.103.3.411

Baumeister, R. F., Exline, J. J. \& Sommer, K. L. (1998). The victim role, grudge theory, and two dimensions of forgiveness. In E. L. Worthington, Jr. (Ed.), Dimensions of forgiveness: psychological research and theological principles, Philadelphia: Templeton Foundation Press. pp. 79-106.

Berry, J. W. \& Worthington, E. L., Jr. (2001). Forgivingness, relationship quality, stres while imagining relationship events, and physical and mental health. Journal of Counseling Psychology, 48, 447-455. http://dx.doi.org/10.1037/0022-0167.48.4.447

Breen, W. E., Kashdan, T. B. , Lenser, M. L. \& Fincham , F. D. ( 2010 ) Gratitude and forgiveness: convergence and divergence on self-report and informant ratings . Personality and Individual Differences, 49, 932 - 937. http://dx.doi.org/10.1016/j.paid.2010.07.033

Brown, R. P. (2003). Measuring individual differences in the tendency to forgive: Construct validity and links with depression. Personality and Social Psychology Bulletin, 29, 759-771. http://dx.doi.org/10.1177/0146167203252882

Bugay, A.\& Demir, A. (2012). Affetme Arttırılabilinir mi?: Affetmeyi Geliştirme Grubu. Türk Psikolojik Danışma ve Rehberlik Dergisi, 4(37), 96-106.

Bugay, A., Demir, A. \& Delevi, R. (2012). Assessment of reliability and validity of the Turkish version of Heartland forgiveness scale 1. Psychological reports, 111(2), 575-584. http://dx.doi.org/10.2466/08.21.PR0.111.5.575-584

Ceyhan, A. A. (2011). İnternet kullanma temel nedenlerine göre üniversite öğrencilerinin problemli internet kullanımı ve algıladıkları iletişim beceri düzeyleri. Kuram ve Uygulamada Eğitim Bilimleri, 11(1), 59-77.

Chan, D. W. (2013). Subjective well-being of Hong Kong Chinese teachers: The contribution of gratitude, forgiveness, and the orientations to happiness. Teaching and Teacher Education, 32, 22-30. http://dx.doi.org/10.1016/j.tate.2012.12.005

Çardak, M. (2012). "Investigation of the effects of the psycho-education curriculum to enhance the tendency of forgiveness on intolerance to uncertainty, psychological well-being, persistent anxiety and anger", (Unpublished doctoral dissertation), Sakarya: Sakarya University

Diener, E. (2000). Subjective well-being: The science of happiness and a proposal for a national index. American Psychologist, 55, 34-43. http://dx.doi.org/10.1037/0003-

Diener, E., Emmons, R. A., Larsen, R. J. \& Griffin, S. (1985). The satisfaction with life scale. Journal ofPersonality Assessment, 49, 71-75. http://dx.doi.org/10.1207/s15327752jpa4901_13. 
Diener, E. \& Suh, E. (1997). Measuring quality of life: Economic, social and subjective indicators. Social Indicators Research, 40, 189-216. http://dx.doi.org/10.1023/A:1006859511756

Diener, E., Oishi, S. \& Lucas, R. E. (2003). Personality, Culture, and Subjective Well-being: Emotional and $\begin{array}{llllll}\text { Cognitive } & \text { Evaluations }\end{array}$ http://dx.doi.org/10.1146/annurev.psych.54.101601.145056

Dwiwardani, C.,Hill, P. C., Bollinger, R. A., Marks, L. E., Steele, J. R., Doolin, H. N. \& Davis, D. E. (2014). Virtues Develop From a Secure Base: Attachment and Resilience as Predictors of Humility, Gratitude, and Forgiveness. Journal of Psychology and Theology, 42(1), 87.

Eaton, J., Struthersi C. W., Shomrony, A. \& Santelli, A. G. (2007). When Apologies Fail: The Moderating Effect of Implicitand Explicit Self-esteem on Apology and Forgiveness. Self and Identity, (6), 209 - 222. http://dx.doi.org/10.1080/15298860601118819

Emmons, R. A., \& McCullough, M. E. (2003). Counting blessings versus burdens: an experimental investigation of gratitude and subjective well-being in daily life. Journal of Personality and Social Psychology, 84, 377-389. http://dx.doi.org/10.1037/0022-3514.84.2.377

Enright, R. D. (1996). Counseling within the forgiveness triad: On forgiving, receiving forgiveness, and $\begin{array}{lllll}\text { self-forgiveness. } & \text { Counseling }\end{array}$ http://dx.doi.org/10.1002/j.2161-007X.1996.tb00844.x

Finkel, E. J., Rusbult, C. E., Kumashiro, M. \& Hannon, P. (2002). Dealing with betrayal in close relationships: Does commitment promote forgiveness? Journal of Personality and Social Psychology, 82, 956-974. http://dx.doi.org/10.1037/0022-

Lambert, N. M., Fincham, F. D., Braithwaite, S. R., Graham, S. M. \& Beach, S. R. (2009). Can prayer increase gratitude? Psychology of Religion and Spirituality, 1(3), 139-149. http://dx.doi.org/10.1037/a0016731

Lawler-Row, K. A., Hyatt Edwards, L., Wuensch, K. L. \& Karremans, J. C. (2011). Forgiveness and health: The role of attachment. Personal Relationships, 18(2), 170-183. http://dx.doi.org/10.1111/j.1475-6811.2010.01327.x

Levinsohn, P.M., Redner, J.E. \& Seeley JR (1991). The relationship between life satisfaction and psychosocial variables: New perspectives. Subjective well-being: An interdisciplinary perspective. F. Strack, M. Argyle, N. Schwarz (Ed), Oxford. Pergamon Press, s. 141-69.

Makinen, J. A. \& Johnson, S. M. (2006). Resolving attachment injuries in couples using emotionally focused therapy: steps toward forgiveness and reconciliation. Journal of Consulting and Clinical Psychology, 74(6), 1055. http://dx.doi.org/10.1037/0022-

McCullough, M. E., Emmons, R. A. \& Tsang, J. A. (2002). The grateful disposition: A conceptual and empirical topography. Journal of Personality and Social Psychology, 82(1), 112-127. http://dx.doi.org/10.1037/0022-3514.82.1.112

McCullough, M. E. \& Hoyt, W. T. (2002) Transgression-related motivational dispositions: personality substrates of forgiveness and their links to the Big Five. Personality and Social Psychology Bulletin, 28, 1556 - 1573. http://dx.doi.org/10.1177/014616702237583

McCullough, M.E., Kilpatrick, S.D., Emmons, R.A. \& Larson, D.B. (2001) "Is Gratitude a Moral Affect?" Psychological Bulletin, 127(2), 249-266. http://dx.doi.org/10.1037/0033-2909.127.2.249

McCullough, M. E., Tsang, J-A. \& Emmons, R. A. (2004) Gratitude in intermediate affective terrain: links of grateful moods to individual differences and daily emotional experience. Journal of Personality and Social Psychology, 86, 295 - 309. http://dx.doi.org/10.1037/0022-

McCullough, M. E. \& Witvliet, C. V. O. (2002). The psychology of forgiveness. In C. R. Snyder ve S. Lopez (Eds.), Handbook of Positive Psychology (446- 458). New York: Oxford University Press.

Myers, D. G. \& Diener, E. (1995). Who is Happy? Psychological Science. 6, 10-19. http://dx.doi.org/10.1111/j.1467-9280.1995.tb00298.x

Sanford, N. (1962). The American college. New York: Wiley.

Sanford, N. (1966). Self and society: Social changes and individual development. New York: Atherton Press. 
Sheldon, K. M. \& Lyubomirsky, S. (2006). How to increase and sustain positive emotion: The effects of expressing gratitude and visualizing best possible selves. The Journal of Positive Psychology, 1(2), 73-82. http://dx.doi.org/10.1080/17439760500510676

Strelan, P. \& Covic, T. (2006). A review of forgiveness process models and a coping framework to guide future research. Journal of Clinical and Social Psychology, 25, 1059-1085. http://dx.doi.org/10.1521/jscp.2006.25.10.1059

Strelan, P. \& Wojtysiak, N. (2009). Strategies for coping with interpersonal hurt: Preliminary evidence for the relationship between coping and forgiveness. Counseling and Values, 53(2), 97-111. http://dx.doi.org/10.1002/j.2161-007X.2009.tb00117.x

Thompson, L. Y., Snyder, C. R., Hoffman, L., Michael, S. T., Rasmussen, H. N. \& Billings, L. S. (2005). Dispositional forgiveness of self, others, and situations. Journal of Personality, 73, 313-359. http://dx.doi.org/10.1111/j.1467-6494.2005.00311.x

Toussaint, L. \& Friedman, P. (2009) Forgiveness, gratitude, and well-being: the mediating role of affect and beliefs. Journal of Happiness Studies, 10, 635 - 654. http://dx.doi.org/10.1007/s10902-008-9111-8

Wade, N. G., Bailey, D. \& Shafer, P. (2005). Helping clients heal: Does forgiveness make a difference? Professional psychology: Research and Practice, 36, 634-641. http://dx.doi.org/10.1037/0735-7028.36.6.634

Worthington, E. L., Berry, J. W. \& Parrott, L. ( 2001 ) Unforgiveness, forgiveness, religion, and health . In T. G. Plante \& A. C. Sherman (Eds.), Faith and health: psychological perspectives. New York: Guilford Press.

Worthington, E. L. \& Scherer, M. (2004). Forgiveness is an emotion-focused coping strategy that can reduce health risks and promote health resilience: Theory, review, and hypotheses. Psychology \& Health, 19(3), 385-405. http://dx.doi.org/10.1080/0887044042000196674

Yüksel, A. \& Oğuz Duran, N. (2012). Turkish adaptation of Gratitude Questionnaire. Eurasian Journal of Educational Research, 46,199-216. 